\title{
MY OWN SPACE. THE STUDY OF OUR CHILDHOOD PLAYGROUND AND THE RULES THAT SELF-REGULATED THE PLAY
}

\author{
Sansebes Radu-Mihai ${ }^{1}$ \\ ${ }^{1}$ S.C. Sannis S.R.L., Brașov (ROMANIA) \\ sansebesradumihai [at] yahoo.com
}

\begin{abstract}
I wanted this exercise of imagination to make a brief analysis of the playground and the way we managed to organize it during childhood. Our space is subjectively centered. It is organized around us and our needs. Most of the time this space is organized around the home. The analysis of our childhood playground focus on the elements and sub-elements that determine the sense of community. My space is defined as the space in which I identify myself, where I find myself, I share memories and I feel a sense of belonging.

The longer time we spend in a certain space, the more we get to know its little secrets, discover it and thus identify with it. The perception of space is subjective, depending on the motivations of each subject and past experiences. We can lear and study the inherited rules from the way we were protecting the garden, retaining the same parking lot or by the way we organised the games in the given space. The space had also to satisfy emotional needs so that the sense of belonging can create social relationships.

Architectural space must be understood as the mental image of the built environment, a space with rules that derive from basic human relations, a space that is organised by feelings and social connections.
\end{abstract}

Keywords: Urban planning, Landscape, Research, The Sense of Community, The Sense of Belonging, Self-Regulating Spaces, Playground Analysis, Social Connections, Child Psychology, Introspection, Memory.

\section{THE STARTING POINT}

I was always intrigued by the way our world is organised and the rules that help our society on working together. I wanted this exercise of imagination to make a brief analysis of the playground and the way we managed to organize it. What makes us to be attracted to a certain space, consider it ours, and give it the name of home? What does this home mean in the end? What makes it so important to us that we can identify with it? Which are the elements that trigger the sense of belonging ${ }^{1}$

\footnotetext{
${ }^{1}$ The sense of belonging derives from the term 'to belong', meaning to be in the right place or a suitable place. Belongingness that is the human emotional need to be an accepted member of a group. A sense of belonging is the feeling of being connected and accepted within one's family and community. It is important in healthy human development and combating behaviour problems and depression.
} 


\section{\#3/2018 URBAN CHALLENGES}

Many studies attempt to investigate rather complicated phenomena in which we appeal concepts, written in a strict way and we often neglect some subjects as they tend to be unimportant for further researches. To be able to effectively work with concepts and to measure the characteristics, we must perform the inverse operation and tie the concepts to reality, so we can measure concepts. Each part of the study must in turn be broken down into sub-dimensions or factors until we can actually measure what we want, by means of some indicators. Values of the nominal variables cannot be ordered; evaluative research seeks to systematically obtain information and evaluate it to provide feed-back about a particular object.

This research started as an introspective of my childhood and the analysis of the surroundings of my home that were transformed into the playground. This space had strict rules, but only with the grown-up mind I managed to decrypt them. I have tried to maintain the structure: methods, results and conclusions.

It is an exploratory research that aims to dig into the past and find the basic rules that mixed the sense of belonging with the playground. These were accomplished for the sole reason of meeting the curiosity and studying the feasibility of conducting a larger study and developing the methodology of such a study. This turned to be an explanatory research that presented the relationship between the elements worked.

Our space is subjectively centred. It is organized around us and our needs. Most of the time this space is organized around the home. It is our centre, the point where we start all the actions and where the discovery of the world begins.

The need for a centre is very strong, as the home is a point of stability and security, and any return home, even in an event-free existence, is filled with emotions and exciting memories.

My space is defined as the space in which I identify myself, where I find myself, I share memories and I feel a sense of belonging. It is an arbitrarily bounded space, but with easily identifiable boundaries, with well-defined and interrelated elements, with subordinate points of interest, capable of self-regulation of the space and relationships taking place within its perimeter. My space is made up of several graduated levels that are organized differently.

My closest space is the space with the strictest organizational rules. The rules are mostly dictated by me and my personal needs. There is also my space with common rules of organization, rules that must serve both my needs and the needs of those with whom I share the space. And there is also my diffused, neighbouring space, with which I identify myself, but in which the rules are dictated by those who share this space and in which I am a simple composing element.

\section{DEFINING RESEARCH}

The analysis of our childhood playground focus on the elements and sub-elements that determine the sense of community. This field and the relation it provides is an important but neglected research element. The reason I started this study was to address this problem and to examine the sense of community, as well as to explore the additional elements and basic rules that organised the space. The support for this theoretical examination was of very limited and derived from the settings being studied, most of them rediscovered from my own memory. 


\section{\#3/2018 URBAN CHALLENGES}

Seymour Bernard Sarason was the first to define the community psychology movement and proposed the term psychological sense of community, a central concept in community psychology. In his vision, the psychological sense of community is "the perception of similarity to others, an acknowledged interdependence with others, a willingness to maintain this interdependence by giving to or doing for others what one expects from them, and the feeling that one is part of a larger dependable and stable structure" [1]

According to D. W. McMillan, and D. M. Chavis, the sense of community is the feeling that members have of belonging to a place or group and matter to one another and to the group. The members share the faith that their needs will be met through commitment and by constantly being together. McMillan focused on the literature on group cohesiveness and proposed the 4 elements that form the sense of community: membership, influence, integration and fulfilment of needs, and shared emotional connection. Their theories are by far the most influential and represent the starting point for most of the recent research in the field [2].

From their studies I concluded the elements and relations that derived from the examples from neighbourhoods or youth-gangs. Sub-elements of these elements work dynamically together to create the "community", that means more than simple residency. ${ }^{2}$ They are presented to illustrate the inter-workings and relation of the elements of a sense of community and represent a starting point for understanding the natural rules that organise the space around the home that is not so well defined but has self-made rules.

\section{SPACE-TIME RELATIONSHIP}

The more time we spend in a certain space, the more we get to know its little secrets, discover it and thus identify with it. The character of space is not subjective, but not objective either, it is an aspect of man's existence in the world. The perception of space is subjective, depending on the motivations of each subject and past experiences. The world is perceived as a sum of events in the four-dimensional space. Each place has a character, a memory - genius loci ${ }^{3}$ [3].

In front of the building, where I used all my energy at an early age, I had countless 'chosen' places. Even now I am intrigued by the anger that we had at the children who were trying to get to the cherry plum tree in the courtyard of the block of flats we lived in or the nuts tree in the parking lot. Why were we so revolted when others wanted something that did not belong to us? Just because it is located near our block of flats does it means that it is ours to have? It was and still is a public space, but by a convention known only to us it became ours.

\footnotetext{
2 The components and the relationship between urban subsystems are more than the sum of the component elements. The whole is greater than the sum of its parts meaning that there is such a connection among the individual items that it is better than what each one would be individually. This is known as synergy.

${ }^{3}$ In classical Roman culture, 'genius loci' represented the protective spirit of a place. This term has been loan from the Latin and it means: 'genius' representing spiritual and 'loci' singular genitive of 'locus', representing the place, that instead of the term representing the special atmosphere composed of a specific place. Alexander Pope turned 'genius loci' an important principle in the product and landscape design. The term was inherited in modern times also in other areas, underpinning the phenomenological research.
} 


\section{\#3/2018 URBAN CHALLENGES}

Why did we feel like we were going to enjoy the cherry plum tree when we did not even care about keeping the garden in shape? We were constrained, or we considered the spring cleaning a game, and the 'feast', our right.

The more time I spent around the familiar elements the more I felt we knew them better and belonged to us. Full of insects and dry for a long time, the willow tree from the block yard was hardly cut. It organized the space in the garden, and its disappearance would have unbalanced the connection and the relationship between the component elements.

In the cutting of the willow tree we saw the deletion of all our memories and games. In addition to it, its disappearance forced us to reorganize the whole space, and the other points of interest were now to take over the activities that had taken place near the willow. All the dominant elements had a major significance and a major role in the ordering of the space. The elements were not just interrelated. Each element had its history and awoken different memories and experiences.

The best example of adhering to inherited rules is that of retaining the same parking lot. We are ashamed to park on the lot of a neighbour who is not at home, because we know it does not belong to us. We are also very revolted when someone is parking on our place, even if that place is declared public space. Any violation of these elements which becomes a rule over time, seems so revolting.

Now every parking lot is sold at an auction and neighbours buy their right to park for a year in their place. Discussions do occur when the parking lot is won by another neighbour and come from the revolt that comes with the change of the natural order of things. We have been accustomed to things in a certain way, to follow a certain pattern, and any change we make, seems to us like a violation of the natural order of things.

\section{SELF-REGULATION}

Certain elements of space organization were inherited and accepted as such. We knew we were not allowed in the neighbouring garden to pick up flowers. I did not know who imposed the rule and why we had to respect it. Each time we deviate from one rule, we take into account the potential repercussions. These rules can be considered as inherited or existing.

But there were new, dynamic elements that reorganized our playground. By cutting the willow tree there was a gap in the organization of the space that had to be filled now. Functions belonging to that area had to be redistributed to other points of interest or created another place to take over the remaining functions. Solutions had to be taken quickly, and sedimentation ought to be made in due time.

Space reorganization was made with short-term solutions when it was just a minor problem that required compromise, or long-lasting when space underwent major changes.

For each ditch dredged to replace a plant we discovered a meaning. The ditch was no longer an obstacle to the game but generated new possibilities. The game was 


\section{\#3/2018 URBAN CHALLENGES}

dynamic and easily adapted to conditions, having the ability to self-adjust the space.

\section{THE SENSE OF BELONGING}

Physical space cannot fully serve the needs of man, so space must also satisfy emotional needs. A sense of belonging can create social relationships. Community representatives feel twin because they share the same space. I feel they have the same concerns and they are a community. The sense of belonging refers to the validation of the importance of cultural life, the cultural experiences of the community as part of the process of inclusion and integration into society. Functional, stable and secure society has a responsibility to provide shelter to those who share the same space.

Good or bad space is ours. We are willing to make compromises and sacrifices to keep it in our possession to remain ours. We do not want our alienation in any way and we are extremely selective when it comes to sharing it with foreigners.

Common space is not just a physical limit, it can be the sum of experiences, events, cultural elements that strengthen relationships among community members. Even shortcomings can generate a strong connection. Although in childhood I cannot complain that I missed something, the little one I had was a common good. You could not go play the new ball and not share it with your friends. The ball was theoretical for you, and practically we were all playing with it. After all, no matter who the ball belonged to because the space in where we played was common, ours. The ball returned to you only when we had to go home.

When we do not get our toys, we improvise. We were even doing a kind of championship, so we could play in a row. When we played Cops and Robbers, the ancestor of Counter Strike, we quickly improvised a new toy for the newcomers. We knew well what the limits of the play area were. Not because we were forced by our parents, but because we were happy to stay there. Further, we would have gone into the playground of others, with whom we did not have much to divide.

Many times, the rules did not even have to be said, because it was self-evident that everyone knew them and respected them. We were not supposed to say that in the Hide-and-Seek game, we should not go further than the neighbouring block. It was normal and we all agreed. Because we would have broken the order of things, and the game would not have been fun and respectful to the others.

When we cross the borders of the territory, we always have a sense of insecurity. Not so afraid of neighbours, but more because it was no longer the place where we played our games - our space.

\section{BORDERS REINFORCE THE DEFINITION OF AREAS}

We knew exactly what our playing area was and how we were allowed to move away. Probably the borders were fixed by the big ones, but they were mostly dictated by our need to spend time in a familiar space. There have been times when we have escaped from these borders, in order to finally turn around and change the space according to our needs. We broke free of the restrictions to play 


\section{\#3/2018 URBAN CHALLENGES}

table tennis and basketball and we were very disturbed that we had to leave the game because we were on a foreign land, where home rules no longer applied.

Although the distance was very small, the differences were quite large. Each area had its own rules for games. There were, of course, a set of general rules for organizing the game, but there were small new elements that made the game to be closer to us, to identify with it.

The boundaries of the area were not clearly demarcated, but we could all guess where the border was. I had a landmark (the stairs, the street, the neighbour building), but you could not say that nobody was playing, or you were not allowed to go on the border.

\section{MY CLOSE SPACE}

The sense of belonging and sense of ownership determine my closest space. It is the space with which we identify and organize ourselves as we please. It is also the space with the strictest rules of organization dictated largely by personal needs.

The disorder of the room or the office does not bother us so hard, because it is ours. We also have a plausible explanation, a reason why it's so messy. The order and cleanliness are necessary and desirable, but for various reasons we fail to reach them. They are desirable but hard to reach, and excuses and motivations are able to find them faster than the energy of doing something in this sense.

The mess, as anything we do, does not bother us as much as it disturbs others. Because we in it see the effort to keep it, the lack of time, the stress and the agitation that generated it.

We are disturbed when someone ruins our mess. Not because he is trying to help us, but because he changes the order of things. Even if the papers are all on the desk, we know exactly where to look for what we need - it's an organized mess. When they are "abducted" by us and put back, we are revolted because we cannot find them anywhere we know where they should be.

The disorder, though it seems a chaotic way of organizing, is actually a product of our work. It is a way of organizing objects, which at the moment does not bother us because in the order of priorities at that time, the cleanliness is placed in the last place. Once the other actions have been punctuated and disorder is no longer justified, we correct these imperfections of the creative process and remedy the normal order of things. Sometimes, because it is too often placed in the priority queue, it gets to bother us and mess up our creative process.

\section{TOTAL SPACE}

Architectural space must be understood as a concretization of the mental image of the built environment. Human existence is so dependent on this mental picture, and the image must be coherent and offer multiple meanings and interpretations. Christian Norberg Schulz's conclusion is categorical. The concepts of home, city, country are still valid. The man has to sit in a place to leave and return to. Outside of personal space, the other places become a continuation of their own existential 


\section{\#3/2018 URBAN CHALLENGES}

space. There is no precise limit, an interruption between the inside and the outside.

The stronger and more decisive the strength of the trend, the more the need for personalization increases. The modelling of space according to its own needs also determines the modification of the individual according to the characteristics of the space. In a certain way each person is the creator of the space in which he lives.

How can we then consider the desire to remain in space even when you no longer identify with it. You do not recognize it anymore, but you feel like you're part of it. Space needs to be reorganized and you can not leave because you feel that you have betrayed it. When there is no trace of identification with space, the only solution is the choice of another space. The personal need determines my space and they can cause it to change.

Elements seemingly negative for a space can be neglected if context, frame, lived memories are stronger. Although I live in a neighbourhood where the bears often descend from the forest to feed from the containers, I do not think I would move very easily to another place. Even if the area is dangerous, I managed to know it and identify with it. It is a matter of pride that we have bears in the neighbourhood, not a disadvantage.

Man makes architecture, organizing space for himself and sometimes even for his fellow men. Without knowing we organize the playground according to precise rules that we are now able to understand.

"The urban form is always in the context of conditions that, regardless of the future development of the way of life, preserve their constitutive validity" [4].

Observation is one of the oldest research methodologies, and the most used in social sciences. Systematic observation is well suited for the study of nonverbal or spatial behaviours. Being an introspective the research is written in a personal style, with the observer being non-intrusive. This space exists only in the personal and collective memory without any relation in present time.

The sense of community is a powerful force in our society now. The understanding of the sense of community can improve the treatment programs and improving integration strategies. Communities are now fencing themselves for protection, unaware of the power of the self-regulating playground. Some neighbourhoods are advertised as exclusive and so they create a social separation.

We must find a way to build communities based on good principles and tolerance, rather than on fear and money. We must learn to use this as a tool for social cooperation. I also hope that my research on this topic will act as a starting point for other community researches and help improve the word we are living in. the best way of improving the social relations is by understanding the past and decompose the elements that created the environment we used to live and play, understand the interconnections and define the concepts that will help others recreate the world we would like to live.

Author's note: The references from 1 to 4 have a direct affiliation in the text, the remaining seven have not. All the references were inspiration and helped in this study. 


\section{References}

[1] Sarason, S. B. (1974), The Psychological Sense of Community: Prospects for a Community Psychology. The Jossey-Bass Behavioral Science Series. Jossey-Bass Publishers, San Francisco (CA), p. 157.

[2] McMillan, D. W. and Chavis, D. M. (1986), "Sense of Community: A Definition and Theory", Journal of Community Psychology, 14, 1, pp. 6-23.

[3] Norberg-Schulz, C. (1971), Existence, Space and Architecture, Praeger Publishers, New York (NY) and Washington, DC.

[4] Sandu, A. M. (2007), The Growing Seed, Arhitext Foundation Publishing House, Bucharest.

[5] Ioan, A. (2010), "Spațiu striat versus situri ale refugiului" ["Uneven Space Versus Refuge Sites", Ph.D Course, 'Ion Mincu' University of Architecture and Urban Planning, Bucharest.

[6] Bancu, Ș. (n/a), "Social Psychology", University Course, The School of Psychology and Education Sciences, 'Alexandru Ioan Cuza' University, Iași.

[7] Canciovici, C. (2017), "Urbanism în cotidianul copilului. Joaca - instrument al proiectării și amenajării spațiului public urban în zonele rezidențiale" ["Urbanism in The Child's Daily Space. Play - A Tool for Designing and Developing Public Urban Space in Residential Areas"], Doctoral Dissertation, 'Ion Mincu' University of Architecture and Urban Planning, Bucharest.

[8] Pleșu, A. (2016), "Sentimentul apartenenței" ["The Sense of Belonging"], Dilema Veche, $640,26^{\text {th }}$ of May $-2^{\text {nd }}$ of June.

[9] Sansebeș, R. M. (2017), Brașov - A Study of Urban Planning and Architecture. Evolution of Brasov in Modern Times. Urban Interventions in the Period 1850-2015, Doctoral Dissertation, 'Ion Mincu' University of Architecture and Urban Planning, Bucharest (unpublished).

[10] Wright, S. P. (2004), Exploring Psychological Sense of Community in Living-Learning Programs and in the University as a Whole, Doctoral Dissertation, University of Maryland, College Park (MD).

[11] Wikipedia, the online free encyclopedia (2018), "Sense of Community". Available at: http://en.wikipedia.org/wiki/Sense_of_community [29.03.2018].

Article distributed under a Creative Commons AttributionNonCommercial-NoDerivatives 4.0 International License (CC BY-NC-ND).

Received: March 30, 2018

Accepted: April 20, 2018. 